\title{
Applying the International Classification of Functioning, Disability and Health framework to determine the predictors of falls and fractures in people with osteoarthritis or at high risk of developing osteoarthritis: data from the Osteoarthritis Initiative
}

Sze-Ee Soh ${ }^{1,2^{*}}$ (D) Anna L. Barker ${ }^{1,3}$, Renata T. Morello ${ }^{1}$ and llana N. Ackerman ${ }^{1}$

\begin{abstract}
Background: Falls are a major cause of injury and death among older people. Evidence suggests that people with osteoarthritis $(O A)$ are at a higher risk of falls and fall-related injuries including fractures. While studies demonstrate a link between OA and falls, little is known about the pathways that link falls with demographic factors, OA impairments, activity limitations and participation restrictions. The aim of this study was to identify risk factors for falls and fractures among people with OA or at high risk of developing OA using the International Classification of Functioning, Disability and Health (ICF) framework.

Methods: A longitudinal analysis of data from the Osteoarthritis Initiative (OAI) dataset was undertaken. Participants were considered to have OA if they reported they had been diagnosed with knee or hip OA by a medical practitioner. Outcomes were self-reported falls and fractures. Potential predictors were classified using the ICF framework. Poisson regression models were used to determine the risk factors for falls and fractures.

(Continued on next page)
\end{abstract}

\footnotetext{
* Correspondence: Sze-Ee.Soh@monash.edu

'Department of Epidemiology and Preventive Medicine, Monash University,

553 St Kilda Road, Melbourne, Vic 3004, Australia

${ }^{2}$ Department of Physiotherapy, Monash University, 47-49 Moorooduc

Highway, Frankston, Vic 3199, Australia

Full list of author information is available at the end of the article
}

C C The Author(s). 2020 Open Access This article is licensed under a Creative Commons Attribution 4.0 International License, which permits use, sharing, adaptation, distribution and reproduction in any medium or format, as long as you give appropriate credit to the original author(s) and the source, provide a link to the Creative Commons licence, and indicate if changes were made. The images or other third party material in this article are included in the article's Creative Commons licence, unless indicated otherwise in a credit line to the material. If material is not included in the article's Creative Commons licence and your intended use is not permitted by statutory regulation or exceeds the permitted use, you will need to obtain permission directly from the copyright holder. To view a copy of this licence, visit http://creativecommons.org/licenses/by/4.0/. The Creative Commons Public Domain Dedication waiver (http://creativecommons.org/publicdomain/zero/1.0/) applies to the data made available in this article, unless otherwise stated in a credit line to the data. 
(Continued from previous page)

Results: Of the 4796 participants, 2270 (47\%) were diagnosed with knee and/or hip OA. A higher proportion of participants with OA reported having had falls (72\% vs 63\%; $p<0.0001$ ) and fractures (17\% vs $14 \% ; p=0.012$ ) than those without OA. Personal factors were found to be stronger predictors of falls and fractures compared to $O A$ impairments, activity limitations and participation restrictions in this sample of participants. After adjusting for potential covariates, self-reported history of falls was a significant predictor of both increased falls (incidence rate ratio [IRR] 1.50; 95\% confidence interval [Cl] 1.40,4.60) and fracture risk (IRR 1.38; 95\% Cl 1.13, 1.69).

Conclusions: By applying the ICF framework, we have shown that personal factors were more likely to predict falls and fractures rather than OA impairments, environmental factors, activity limitations and participation restrictions in people with $\mathrm{OA}$ or at high risk of developing OA. This highlights the importance of questioning patients about their previous falls and past medical history, and using this information to focus our assessment and clinical decision-making processes.

Keywords: Falls, Fractures, Osteoarthritis, Older people

\section{Background}

Falls are a major cause of injury, hospitalisation and death among older people worldwide $[1,2]$. In the United States, it is estimated that approximately 30,000 adults over the age of 65 died as a result of a fall in 2016 [3]. In England, falls have been found to be the ninth highest cause of disability-adjusted life years and the leading cause of injury in 2013 [4]. There is growing evidence that people with osteoarthritis (OA) may be at a higher risk of falls, injurious falls and fall-related injuries including fractures [5-9]. Osteoarthritis is one of the most disabling musculoskeletal conditions among older people with profound impacts on their mobility and ability to work and participate in social roles [10]. Many of the physical impairments associated with $\mathrm{OA}$ are also known risk factors for falls such as reduced strength and balance [11, 12]. However, previous studies examining the association between $\mathrm{OA}$ and falls have not always considered or conceptualised the pathways that link falls with demographic factors, impairments, activity limitations and participation restrictions $[6$, $8,9,13,14]$. This makes it challenging to draw conclusions about the ways in which a condition such as OA might contribute to a person's risk of falls and fractures, and to provide relevant clinical recommendations.

The International Classification of Functioning, Disability and Health (ICF) is a theoretical framework that describes the components of health and health-related domains, including for people with chronic conditions such as OA [15]. The multi-perspective approach adopted by the ICF is a useful way to classify the symptoms and outcomes related to OA (Additional file 1, available online), as well as the potential risk factors or predictors of falls and fractures. The aim of this study was to identify the risk factors for falls and fractures using the ICF framework among people with OA or at high risk of developing $\mathrm{OA}$, allowing us to better understand the potential contribution of demographic characteristics, lifestyle behaviours, and $\mathrm{OA}$ symptoms and impairments.

\section{Methods}

Data source and participants

This was a retrospective analysis of de-identified data obtained from the Osteoarthritis Initiative (OAI) database (https://nda.nih.gov/oai), a prospective longitudinal cohort study. The OAI comprises data from 4796 participants aged 45-79 years recruited from four clinical sites in the United States. Details regarding the OAI are described in detail elsewhere [16]. For this current longitudinal analysis, we considered participants to have OA if they reported that they had been diagnosed with hip or knee OA by a medical practitioner (clinical diagnosis with or without radiological evidence) within 12 months of the corresponding data collection period [8]. The non-OA comparator group comprised of participants in the OAI who were at high risk of developing OA but had not yet been diagnosed with the condition. Specific datasets used were $0.2 .2,0.2 .3,1.2 .1,3.2 .1,5.2 .1,6.2 .1$, 8.2.1 and 10.2.1. Ethics approval was obtained from Monash University Human Research Ethics Committee (MUHREC Project Number 11755).

\section{Measurement of falls and fractures}

All participants in the OAI dataset were asked to selfreport if they had a fall and landed on the floor or ground in the last 12 months annually from baseline to year 4 , and then at the year 6 and 8 visits. Participants were classified as having fallen if they responded affirmatively to this question at any time point. At the same time intervals, participants were asked if they had been told by a doctor that they fractured a bone. If they responded affirmatively to this question at any time point, they were considered to have a fracture.

\section{Predictors of falls and fracture risk}

Demographic, clinical and physiological data were collected from all OAI participants annually from baseline through to year 8 . We derived key predictors of falls and 
fractures from published systematic review evidence on community-dwelling older adults [17]. Potential predictor variables at baseline were extracted from the OAI dataset and mapped to the ICF domains of impairments in body structures and functions, activity limitations, participation restrictions, and environmental and personal factors (Fig. 1). Personal and environmental factors included demographic and clinical characteristics such as age, sex, marital status, living situation, number of comorbidities [18], use of opioids and bisphosphonates, depression [19], and self-reported history of falls. Symptoms associated with knee and/or hip OA such as pain [20], stiffness [21], strength [22, 23], limitations in performing self-care activities of daily living [21] and mobility [24-26] were also examined in relation to falls and fractures. Difficulties relating to recreation [20] and being able to undertake physical activity [27] represent participation restrictions that were also examined as potential predictors of falls and fractures. All predictor variables are presented in Additional file 2 (available online).

\section{Data analysis}

Analysis was performed using Stata/IC15.1 (StataCorp College Station, Texas, USA). Descriptive statistics were used to summarise the characteristics for all participants. Fall and fracture events were also described for all participants in the study. A three-step modelling approach was used to determine the factors associated with increased falls and fracture risk. First, univariate Poisson regression models for falls risk and fracture risk and potential predictors in each ICF domain (Fig. 1) were computed with a robust variance estimator. Second, factors with a moderate association $(p \leq 0.10)$ with the outcome (falls or fracture risk) on univariate analysis were entered into a multivariate model based on their ICF domains and retained if $p \leq$ 0.05 [28]. Highly correlated predictors were identified by the variance inflation factor (VIF) as an indicator of collinearity, and when collinearity was identified (VIF $>2.5$ ) only the variable with the higher $\mathrm{R}^{2}$ on univariate analysis was retained for entry into the multivariate model. A final model was computed using all significant variables identified from each ICF domain. We calculated exposure time for each participant from the date of OA diagnosis or study enrolment to the date of survey where the last fall or fracture event was reported. The dependent variable for each model was falls or fracture status following OA diagnosis. Thus, individuals diagnosed with knee or hip OA during the year 8 visit were excluded from analysis because there was no post-diagnosis record of falls and fractures. Interactions between the presence of knee or hip $\mathrm{OA}$ and the remaining predictors were also examined.

\section{Results}

\section{Participant characteristics}

Of the 4796 participants in the OAI, 2270 (47\%) were diagnosed with knee and/or hip OA by a medical practitioner. Specifically, 1460 participants $(30 \%)$ reported having been diagnosed with knee OA, while 245 participants (5\%) had hip OA and 565 (12\%) had both knee and hip OA. The characteristics of participants in the $\mathrm{OA}$ and non-OA cohorts were broadly similar (Table 1), although there was a higher percentage of participants

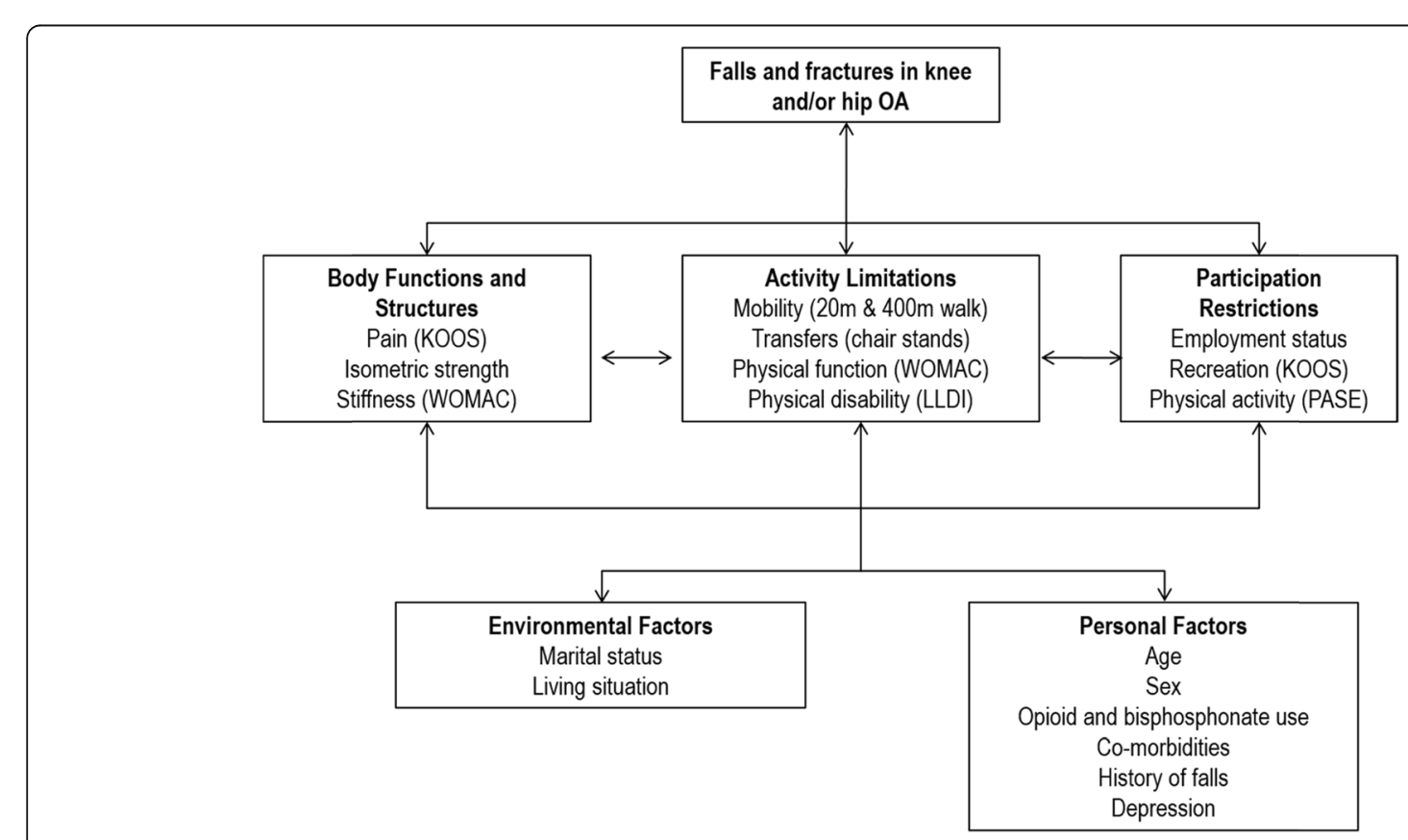

Fig. 1 Potential predictors of falls and fractures in people with knee and/or hip OA classified into ICF domains 
Table 1 Demographic and clinical characteristics of study participants, mapped to the International Classification of Functioning, Disability and Health (ICF) framework

\begin{tabular}{|c|c|c|c|c|}
\hline \multirow{2}{*}{ Fall and fracture outcomes } & \multicolumn{2}{|c|}{ OA participants $(n=2270)^{a}$} & \multicolumn{2}{|c|}{ Non-OA participants $(n=2526)$} \\
\hline & & & & \\
\hline Self-reported fallers, $n$ (\%) & 1627 & 72 & 1596 & 63 \\
\hline Self-reported history of fracture, $n(\%)$ & 382 & 17 & 359 & 14 \\
\hline \multicolumn{5}{|l|}{ Personal factors } \\
\hline Age, mean (SD) & 62.0 & 8.9 & 60.4 & 9.4 \\
\hline Female, $n(\%)$ & 1405 & 62 & 1399 & 55 \\
\hline \multicolumn{5}{|l|}{ Number of co-morbid conditions, $n(\%)$} \\
\hline None & 1171 & 73 & 1489 & 79 \\
\hline One or more & 445 & 28 & 406 & 21 \\
\hline Depression, mean (SD) & 7.3 & 7.5 & 6.0 & 6.5 \\
\hline Opioid use, $n(\%)$ & 218 & 10 & 36 & 1 \\
\hline Bisphosphonate use, $n$ (\%) & 291 & 13 & 285 & 11 \\
\hline Previous history of falls, $n$ (\%) & 933 & 41 & 774 & 31 \\
\hline \multicolumn{5}{|l|}{ Environmental factors } \\
\hline Married, $n(\%)$ & 1466 & 65 & 1712 & 68 \\
\hline Lived alone, $n(\%)$ & 515 & 23 & 540 & 21 \\
\hline \multicolumn{5}{|c|}{ Impairments in body function and structures (OA impairments) } \\
\hline KOOS pain scale, mean (SD) & 72.0 & 20.3 & 84.1 & 16.4 \\
\hline WOMAC stiffness scale, mean (SD) & 2.5 & 1.8 & 1.5 & 1.5 \\
\hline Flexor strength (N/kg), mean (SD) & 1.8 & 0.8 & 2.0 & 0.2 \\
\hline Extensor strength (N/kg), mean (SD) & 4.4 & 1.5 & 4.8 & 1.5 \\
\hline \multicolumn{5}{|l|}{ Activity limitations } \\
\hline WOMAC physical function scale, mean (SD) & 14.6 & 13.2 & 7.4 & 9.9 \\
\hline Chair stands (stands/seconds, mean (SD) & 0.5 & 0.1 & 0.5 & 0.2 \\
\hline 20 m walk test (m/seconds), mean (SD) & 1.3 & 0.2 & 1.3 & 0.2 \\
\hline 400 m walk test (seconds), mean (SD) & 313.9 & 60.6 & 300.8 & 53.5 \\
\hline \multicolumn{5}{|l|}{ Participation restrictions } \\
\hline Employed, $n$ (\%) & 1326 & 58 & 1671 & 66 \\
\hline Physical activity (PASE), mean (SD) & 155.9 & 82.8 & 165.3 & 82.0 \\
\hline KOOS sport and recreation scale, mean (SD) & 63.8 & 27.1 & 79.4 & 22.7 \\
\hline
\end{tabular}

OA osteoarthritis, SD standard deviation, KOOS Knee injury and Osteoarthritis Outcome Score, WOMAC Western Ontario and McMaster Universities Osteoarthritis Index, PASE Physical Activity Scale for the Elderly

Significant results $(\boldsymbol{p} \leq \mathbf{0 . 0 5})$ in bold

${ }^{a}$ Of these, 131 participants were diagnosed with $O A$ at Year 8 visit and excluded from further analysis

with OA using opioid analgesics $(p<0.0001)$ and selfreported a history of falls $(p<0.0001)$. Participants in the OA cohort also reported having more knee pain $(p<$ $0.0001)$, were less physically active $(p<0.0001)$, and had more difficulties performing self-care activities $(p<$ $0.0001)$ and participating in sports and recreational activities $(p<0.0001)$. Analysis of fall and fracture data revealed a significantly higher proportion of fallers among those with knee and/or hip OA compared to those without $(p<0.0001)$. There was also a significantly higher proportion of participants with knee or hip OA who reported having had a fracture $(p=0.012)$.
Predictors of falls and fracture risk

All personal and environmental factors, OA impairments, activity limitations and participation restrictions examined in the univariate analyses had a moderate association with increased falls risk $(p \leq 0.10)$. However, in the multivariate models for each ICF domain, the only statistically significant personal factors were age, sex, self-reported history of falls and depression (Table 2). Living alone was a significant environmental factor, while extensor strength was the only OA impairment that significantly contributed to falls risk. The time taken to walk $400 \mathrm{~m}$ and the ability to participate in sport and 
Table 2 Univariate and multivariate regression analyses of factors associated with increased falls and fracture risk

\begin{tabular}{|c|c|c|c|c|c|c|c|c|c|c|c|c|}
\hline & \multicolumn{6}{|c|}{ Risk of falls } & \multicolumn{6}{|c|}{ Risk of fractures } \\
\hline & \multicolumn{2}{|c|}{ Univariate analysis } & \multicolumn{2}{|c|}{ Multivariate analysis } & \multicolumn{2}{|c|}{ Final model } & \multicolumn{2}{|c|}{ Univariate analysis } & \multicolumn{2}{|c|}{ Multivariate analysis } & \multicolumn{2}{|c|}{ Final model } \\
\hline & IRR & $95 \% \mathrm{Cl}$ & IRR & $95 \% \mathrm{Cl}$ & IRR & $95 \% \mathrm{Cl}$ & IRR & $95 \% \mathrm{Cl}$ & IRR & $95 \% \mathrm{Cl}$ & IRR & $95 \% \mathrm{Cl}$ \\
\hline \multicolumn{13}{|l|}{ Presence of OA } \\
\hline Knee OA only & 0.97 & $0.91,1.04$ & & & 0.92 & $0.85,1.00$ & 0.86 & $0.72,1.02$ & & & 0.73 & $0.56,0.94$ \\
\hline Hip OA only & 1.07 & $0.95,1.21$ & & & 1.01 & $0.88,1.17$ & 1.05 & $0.76,1.45$ & & & 0.81 & $0.52,1.26$ \\
\hline Knee and hip OA & 1.10 & $1.02,1.20$ & & & 0.92 & $0.82,1.03$ & 1.32 & $1.06,1.64$ & & & 0.90 & $0.62,1.29$ \\
\hline \multicolumn{13}{|l|}{ Personal factors } \\
\hline Age & 1.00 & $1.00,1.01$ & 1.00 & $1.00,1.01$ & 1.00 & $1.00,1.01$ & 1.01 & $1.00,1.02$ & 1.01 & $1.00,1.02$ & 1.01 & $1.00,1.02$ \\
\hline Female & 1.17 & $1.10,1.24$ & 1.14 & $1.07,1.22$ & 1.12 & $1.04,1.20$ & 1.46 & $1.25,1.71$ & 1.21 & $0.99,1.46$ & & \\
\hline Previous history of falls & 1.56 & $1.48,1.64$ & 1.51 & $1.42,1.60$ & 1.50 & $1.40,1.60$ & 1.49 & $1.29,1.72$ & 1.28 & $1.07,1.52$ & 1.38 & $1.13,1.69$ \\
\hline Depression & 1.01 & $1.01,1.01$ & 1.01 & $1.00,1.01$ & 1.00 & $1.00,1.01$ & 1.02 & $1.01,1.03$ & 1.01 & $1.00,1.03$ & & \\
\hline$>1$ co-morbid conditions & 1.13 & $1.05,1.21$ & 1.05 & $0.98,1.12$ & & & 1.50 & $1.22,1.76$ & 1.33 & $1.10,1.60$ & 1.45 & $1.17,1.81$ \\
\hline Opioid use & 1.20 & $1.08,1.33$ & 1.07 & $0.95,1.21$ & & & 1.60 & $1.22,2.10$ & 1.35 & $0.96,1.89$ & & \\
\hline Bisphosphonate use & & & & & & & 1.78 & $1.48,2.14$ & 1.64 & $1.32,2.05$ & 1.78 & $1.40,2.27$ \\
\hline \multicolumn{13}{|l|}{ Environmental factors } \\
\hline Married & 0.92 & $0.87,0.98$ & 1.00 & $0.91,1.09$ & & & 0.76 & $0.66,0.89$ & 0.80 & $0.64,1.00$ & & \\
\hline Lived alone & 1.13 & $1.06,1.20$ & 1.13 & $1.02,1.24$ & 1.02 & $0.94,1.10$ & 1.30 & $0.10,1.53$ & 1.08 & $0.84,1.38$ & & \\
\hline \multicolumn{13}{|c|}{ Impairments in body function and structures } \\
\hline Knee pain & 1.00 & $0.99,1.00$ & 1.00 & $1.00,1.00$ & & & 1.00 & $0.99,1.00$ & 1.00 & $0.99,1.00$ & & \\
\hline Knee stiffness & 1.03 & $1.01,1.04$ & 1.02 & $1.00,1.05$ & & & 1.05 & $1.00,1.09$ & 1.02 & $0.96,1.09$ & & \\
\hline Flexor strength & 0.93 & $0.89,0.96$ & & & & & 0.97 & $0.88,1.0$ & & & & \\
\hline Extensor strength & 0.96 & $0.94,0.98$ & 0.97 & $0.94,0.99$ & 0.99 & $0.97,1.02$ & 0.95 & $0.90,1.00$ & 0.96 & $0.90,1.01$ & & \\
\hline \multicolumn{13}{|l|}{ Activity limitations } \\
\hline Physical function & 1.00 & $1.00,1.01$ & 1.00 & $1.00,1.00$ & & & 1.00 & $1.00,1.01$ & 1.00 & $0.99,1.00$ & & \\
\hline Chair stands & 0.72 & $0.59,0.87$ & 0.81 & $0.64,1.01$ & & & 0.81 & $0.46,1.43$ & & & & \\
\hline $20 \mathrm{~m}$ walk test & 0.82 & $0.73,0.93$ & 1.03 & $0.85,1.25$ & & & 0.50 & $0.35,0.71$ & 0.58 & $0.34,0.99$ & 0.85 & $0.51,1.42$ \\
\hline $400 \mathrm{~m}$ walk test & 1.00 & $1.00,1.00$ & 1.00 & $1.00,1.00$ & 1.00 & $1.00,1.00$ & 1.00 & $1.00,1.00$ & 1.00 & $1.00,1.00$ & & \\
\hline \multicolumn{13}{|l|}{ Participation restrictions } \\
\hline Employed & 0.90 & $0.85,0.95$ & 0.94 & $0.87,1.00$ & & & 0.82 & $0.71,0.95$ & 0.89 & $0.74,1.06$ & & \\
\hline Physical activity & 1.00 & $1.00,1.00$ & 1.00 & $1.00,1.00$ & & & 1.00 & $1.00,1.00$ & & & & \\
\hline Sport and recreation & 1.00 & $1.00,1.00$ & 1.00 & $1.00,1.00$ & 1.00 & $1.00,1.00$ & 1.00 & $0.99,1.00$ & 1.00 & $0.99,1.00$ & 1.00 & $0.99,1.00$ \\
\hline
\end{tabular}

$O A$ osteoarthritis, IRR incident rate ratios, $95 \% \mathrm{Cl} 95 \%$ confidence intervals

Final model for falls risk included presence of OA, age, gender, previous history of falls, depression, living situation, extensor strength, mobility limitations (400 m walk test) and difficulties with sport and recreation

Final model for fracture risk included presence of OA, age, previous history of falls, number of co-morbid conditions, bisphosphonate use, mobility limitations (20 $m$ walk test) and difficulties with sport and recreation

Significant results $(\boldsymbol{p} \leq \mathbf{0 . 0 5})$ in bold

recreational activities were also a significant predictor. In the final multivariate model, only personal factors were significantly associated with increased falls risk. The strongest predictors were self-reported history of falls (incidence rate ratio [IRR] 1.50; 95\% confidence interval [CI] 1.40, 4.60) and female sex (IRR 1.12; 95\% CI 1.04, 1.20). The presence of OA was not an independent predictor of falls risk.

For the fracture risk analyses, all personal and environmental factors examined had a moderate association on univariate analyses $(p>0.10)$ but in terms of OA impairments, flexor strength was not a significant predictor. Limitations in time taken to stand five times and participation in physical activity were also not associated with fracture risk on univariate analysis. The multivariate models for each ICF domain demonstrated that the significant personal factors that predicted fracture risk were age, self-reported history of falls, having more than one co-morbidity and bisphosphonate use (Table 2). Amongst the activity limitations and participation restrictions 
examined, a $1 \mathrm{~m} / \mathrm{s}$ increase in the speed taken to walk 20 $\mathrm{m}$ and ability to participate in sport and recreational activities were significantly associated with the risk of fractures. However, when these variables were included in a final multivariate model, only personal factors remained as significant predictors. Bisphosphonate use (IRR 1.78; 95\% CI 1.40, 2.27), having more than one co-morbidity (IRR 1.45; $95 \%$ CI 1.17, 1.81) and self-reported history of falls (IRR 1.38 ; $95 \%$ CI 1.13, 1.69) were personal factors that contributed significantly to fracture risk. The presence of OA (specifically knee OA) was found to not be associated with increased fracture risk (IRR 0.73; 95\% CI 0.56, 0.94).

Sensitivity analyses were conducted to examine the factors associated with the risk of recurrent falls and fractures. Participants who self-reported that they had a fall at two or more time points during the OAI study period were considered to be recurrent fallers. Likewise, participants who reported that they had fractured a bone at more than two time points were considered to have recurrent fractures. Similar to the model for increased falls risk, the strongest predictors for recurrent falls were a self-reported history of falls (IRR 2.09; 95\% CI 1.92, 2.27 ) and female sex (IRR 1.17; 95\% CI 1.07, 1.27). Personal factors also remained as significant predictors for having more than one fracture over the OAI study period. Specifically, self-reported history of falls (IRR 2.11; 95\% CI 1.63, 2.74) and the use of bisphosphonates (IRR 1.88; 95\% CI 1.36, 2.59) and opioids (IRR 1.83; 95\% CI $1.18,2.84$ ) were significantly associated with recurrent fractures. No association was observed between the presence of OA and recurrent falls or fractures. No statistically significant interactions were also observed between the presence of $\mathrm{OA}$ and significant predictors for both falls and fracture risk.

\section{Discussion}

This study has applied the ICF framework to classify potential predictors for falls and fractures among people with OA or at high risk of developing OA. We have systematically considered the complexity of $\mathrm{OA}$ and adopted a biopsychosocial approach to describe the demographic characteristics, lifestyle behaviours and OA symptoms that may be associated with falls and fractures. Our findings indicate that personal factors are more likely to predict falls and fracture rather than OA impairments, environmental factors, activity limitations and participation restrictions. This has implications for how clinicians can efficiently structure their clinical assessments when evaluating falls risk.

Of the personal factors that were examined, selfreported history of falls was a consistent risk factor for both falls and fractures, It was also associated with an increased risk of having more than one fall or fracture over the study period.. This is consistent with previous research involving community-dwelling older adults which has shown that a history of falls is the single strongest predictor of falls, including recurrent falls [17]. Older adults who have previously fallen or who stumble frequently are two to three times more likely to fall within the next year [17]. In addition, having co-morbidities, using bisphosphonates and using opioids were found to be significant predictors of increased fracture risk. We appreciate that this finding is not necessarily novel given that self-reported history of falls, greater co-morbidity and opioid use are well-established risk factors for future falls $[17,29]$. The association between fracture risk and bisphosphonates is also likely due to confounding by indication as bisphosphonates are commonly prescribed to people at increased risk of fractures. Nevertheless, by using the ICF as a framework and taking into account the complexity of $\mathrm{OA}$, we have shown that questioning patients about their previous falls, past medical history and medication profile is an essential component of falls and fracture risk screening even when patients may have other symptoms such as reduced strength and mobility. Given that clinicians have limited time for patient consultations and have multiple competing priorities, these questions can be used to assist clinicians focus their assessments and clinical decisionmaking processes.

People who are newly diagnosed with knee or hip OA have been shown to be $50 \%$ more likely to experience a fall and $85 \%$ more likely to experience a fracture 12 months following their diagnosis [8]. Symptomatic knee and hip OA has also been found to be associated with greater odds of future falls [6]. With regard to our study findings that suggested that OA may reduce the risk of fractures, it may be related to participants with OA being less physically active compared to those without the condition. Previous studies have suggested that people with knee and/or hip OA are less likely to fracture because they are less active [30] or are less likely to be in positions where they are at risk of falling and injuring themselves (e.g. walking with a wider base of support or using a gait aid). It is important to note, however, that the association we observed between falls and fracture with physical activity was not statistically significant when other factors were considered. There was also no interaction between physical activity levels and the presence of OA in our study. Although a non-linear association between mobility and falls risk [31] may explain this apparent lack of association, this finding has important clinical implications. Exercise and physical activity are increasingly being recommended to manage OA symptoms and impairments $[8,32]$. We therefore need to ensure that an individual's risk of falling is not inadvertently increased by encouraging them to simply move more, without proper falls risk screening or balance assessment, if indicated. 
Although we considered functional impairments and mobility limitations in our analyses, impaired balance was not examined. Balance measures were assessed in the OAI only at the 10-year visit. There is Level 1 evidence demonstrating that falls risk in older people can be reduced by well-designed exercise programs that includes balance activities [33]. Future studies should include static and dynamic balance tests when examining risk factors for falls and fractures in people with $\mathrm{OA}$, to better inform clinical management. This is because the inclusion of exercises that involve a high challenge to balance may be one way in which we can encourage people with OA to move more without increasing their risk of falling $[8,33]$.

A strength of this study was the large sample of people with falls or fractures and the use of the ICF framework to classify potential risk factors. We have used a biopsychosocial and pathophysiological basis to describe the determinants of falls and fractures including symptoms associated with OA. Nevertheless, some limitations need consideration. As with any secondary data analysis, we were limited to available study variables. The number of falls for each participant was categorised as one, two or three, four or five, and six or more in the OAI dataset. Given the ordinal nature of this variable, we classified those with no falls as a non-faller and those with more than one fall as a faller and binary data were used as an outcome. Additionally, we relied on participants selfreporting falls and fractures at 12-month intervals, which may have resulted in under-reporting of these outcomes [34]. The high proportion of missing data on type and location of fracture [8] also limited our ability to fully describe fractures incurred by the cohort and explore associations between $\mathrm{OA}$ and different fracture types. A further limitation was that the predictors of falls and fractures included this analysis were extracted from the OAI study at baseline (i.e. entry into the study) due to the proportion of missing data over time. This limits our ability to determine how changes in a person's functional status may impact on their falls and fracture risk. Finally, despite including a variety of OA-related impairments, activity limitations and participation restrictions in our analyses, we were unable to explain most of the variance in falls and fracture outcomes. This likely reflects the multitude of complex factors involved, many of which are not directly quantifiable. Our findings therefore highlight the 'wicked' nature of falls and the intricate interactions between behavioural, clinical, physical and psychological factors that contribute to a person's risk of falls and fractures.

\section{Conclusion}

By applying the ICF framework, we have shown that personal factors were most likely to predict the risk of falls and fractures among people with OA or at high risk of developing OA. Specifically, a self-reported history of falls, the presence of co-morbidities and bisphosphonate use were significant contributing factors. This emphasises the importance of clinicians enquiring about previous falls (as well as past medical history and fallsrelevant medication use) when screening for falls and fracture risk.

\section{Supplementary information}

Supplementary information accompanies this paper at https://doi.org/10. 1186/s12891-020-3160-5.

Additional file 1. Examples of the interactions between the ICF domains for hip and knee OA. Adapted with permission from the World Health Organisation [14].

Additional file 2. Predictors of falls and fracture risk.

\section{Abbreviations}

Cl: Confidence interval; ICF: International Classification of Functioning, Disability and Health; IRR: Incidence rate ratio; KOOS: Knee injury and Osteoarthritis Outcome Score; OA: Osteoarthritis; OAl: Osteoarthritis Initiative; PASE: Physical Activity Scale for the Elderly; VIF: Variance inflation factor; WOMAC: Western Ontario and McMaster Universities Osteoarthritis Index

\section{Acknowledgements}

The authors would like to thank Toby Smith who provided advice regarding the data analysis approach.

\section{Authors' contributions}

All authors provided substantial contribution to the conception and design of the project; drafted and revised the article critically for important intellectual content; and approved the final manuscript. SES and RM accepts responsibility for the integrity of the data analysis. SES led drafting of all sections of the article in consultation with RM, INA and ALB.

\section{Funding}

This work was supported by an Arthritis Australia Project Grant. The funding source had no influence on the data collection and analyses, interpretation and decision to publish. The OAI is a public-private partnership comprised of five contracts (N01-AR-2-2258; NOI-AR-2-2259; NO1-AR-2-2260; NOI-AR-2-

2261; NOI-AR-2-2262) funded by the National Institutes of Health, a branch of the Department of Health and Human Services, and conducted by the OAI Study Investigators. Private funding partners include: Merck Research Laboratories; Novartis Pharmaceuticals Corporation, GlaxoSmithKline; and Pfizer, Inc. Private sector funding for the OAl is managed by the Foundation for the $\mathrm{Na-}$ tional Institutes of Health. This manuscript was prepared using an OAI public use dataset and does not necessarily reflect the opinions or views of the OAI investigators, the $\mathrm{NIH}$, or the private funding partners.

\section{Availability of data and materials}

The datasets generated and/or analysed during the current study are available from the Osteoarthritis Initiative (OAI) dataset, (https://nda.nih.gov/ oai), which is publicly available.

Ethics approval and consent to participate

Ethics approval was obtained from Monash University Human Research Ethics Committee (MUHREC Project Number 11755).

Consent for publication Not applicable.

Competing interests

The authors declare that they have no competing interests. 


\section{Author details}

'Department of Epidemiology and Preventive Medicine, Monash University, 553 St Kilda Road, Melbourne, Vic 3004, Australia. ${ }^{2}$ Department of Physiotherapy, Monash University, 47-49 Moorooduc Highway, Frankston, Vic 3199, Australia. ${ }^{3}$ Medibank Private Limited, 720 Bourke Street, Melbourne, Vic 3008, Australia.

Received: 8 September 2019 Accepted: 24 February 2020

Published online: 29 February 2020

\section{References}

1. Beck B, Bray JE, Cameron PA, Cooper DJ, Gabbe BJ. Trends in severe traumatic brain injury in Victoria, 2006-2014. Med J Aust. 2016;204(11):407.

2. Haagsma JA, Graetz N, Bolliger I, Naghavi M, Higashi H, Mullany EC, Abera SF, Abraham JP, Adofo K, Alsharif U, Ameh EA, Ammar W, CAT A, Barrero LH, Bekele T, Bose D, Brazinova A, Catalá-López F, Dandona L, Dandona R, Dargan PI, De Leo D, Degenhardt L, Derrett S, Dharmaratne SD, Driscoll TR, Duan L, Petrovich Ermakov S, Farzadfar F, Feigin VL, Franklin RC, Gabbe B, Gosselin RA, Hafezi-Nejad N, Hamadeh RR, Hijar M, Hu G, Jayaraman SP, Jiang G, Khader YS, Khan EA, Krishnaswami S, Kulkarni C, Lecky FE, Leung R, Lunevicius R, Lyons RA, Majdan M, Mason-Jones AJ, Matzopoulos R, Meaney PA, Mekonnen W, Miller TR, Mock CN, Norman RE, Orozco R, Polinder S, Pourmalek F, Rahimi-Movaghar V, Refaat A, Rojas-Rueda D, Roy N, Schwebel DC, Shaheen A, Shahraz S, Skirbekk V, Søreide K, Soshnikov S, Stein DJ, Sykes BL, Tabb KM, Temesgen AM, Tenkorang EY, Theadom AM, Tran BX, Vasankari TJ, Vavilala MS, Vlassov W, Woldeyohannes SM, Yip P, Yonemoto N, Younis MZ, Yu C, CJL M, Vos T. The global burden of injury: incidence, mortality, disability-adjusted life years and time trends from the Global Burden of Disease study 2013. Inj Prev. 2016;22(1):3.

3. Burns $E$, Kakara R. Deaths from falls among persons aged $\geq 65$ Years: United States, 2007-2016. Morb Mortal Wkly Rep. 2018;67(18):509-14.

4. Newton JN, ADM B, CJL M, Dicker D, Foreman KJ, Wang H, Naghavi M, Forouzanfar MH, Ohno SL, Barber RM, Vos T, Stanaway JD, Schmidt JC, Hughes AJ, DFJ F, Ecob R, Gresser C, McKee M, Rutter H, Abubakar I, Ali R, Anderson HR, Banerjee A, Bennett DA, Bernabé E, Bhui KS, Biryukov SM, Bourne RR, CEG B, Bruce NG, Brugha TS, Burch M, Capewell S, Casey D, Chowdhury R, Coates MM, Cooper C, Critchley JA, Dargan PI, Dherani MK, Elliott P, Ezzati M, Fenton KA, Fraser MS, Fürst T, Greaves F, Green MA, Gunnell DJ, Hannigan BM, Hay RJ, Hay SI, Hemingway H, Larson HJ, Looker KJ, Lunevicius R, Lyons RA, Marcenes W, Mason-Jones AJ, Matthews FE, Moller H, Murdoch ME, Newton CR, Pearce N, Piel FB, Pope D, Rahimi K, Rodriguez A, Scarborough P, Schumacher AE, Shiue I, Smeeth L, Tedstone A, Valabhji J, Williams HC, CDA W, Woolf AD, ACJ D. Changes in health in England, with analysis by English regions and areas of deprivation, 19902013: a systematic analysis for the Global Burden of Disease Study 2013. Lancet. 2015;386(10010):2257-74.

5. Barbour KE, Stevens JA, Helmick CG, Luo Y-H, Murphy LB, Hootman JM, Theis K, Anderson LA, Baker NA, Sugerman DE. Falls and fall injuries among adults with arthritis: United States, 2012. Morb Mortal Wkly Rep. 2014;63(17):379.

6. Dore AL, Golightly YM, Mercer VS, Shi XA, Renner JB, Jordan JM, Nelson AE. Lower-extremity osteoarthritis and the risk of falls in a community-based longitudinal study of adults with and without osteoarthritis. Arthritis Care Res. 2015;67(5):633-9.

7. Hill KD, Williams SB, Chen J, Moran H, Hunt S, Brand C. Balance and falls risk in women with lower limb osteoarthritis or rheumatoid arthritis. J Clin Gerontol Geriatr. 2013;4(1):22-8

8. Smith TO, Higson E, Pearson M, Mansfield M. Is there an increased risk of falls and fractures in people with early diagnosed hip and knee osteoarthritis? Data from the osteoarthritis Initiative. Int J Rheum Dis. 2018; 21(6):1193-201.

9. Barbour KE, Sagawa N, Boudreau RM, Winger ME, Cauley JA, Nevitt MC, Fujii T, Patel KV, Strotmeyer ES. Knee osteoarthritis and the risk of medically treated injurious falls among older adults: the health $A B C$ study. Arthritis Care Res. 2019;71(7):865-74.

10. Briggs A, Woolf A, Dreinhöfer K, Homb N, Hoy D, Kopansky-Giles D, Åkesson K, March L. Reducing the global burden of musculoskeletal conditions. Bull World Health Organ. 2018;96(5):366-8.

11. Ackerman IN, Soh SE, Barker AL. Opportunities for cross-disciplinary care partnerships in physiotherapy. J Physiother. 2018;64(2):69-71.

12. Sherrington $\mathrm{C}$, Tiedemann A. Physiotherapy in the prevention of falls in older people. J Physiother. 2015;61(2):54-60.
13. Scott D, Blizzard L, Fell J, Jones G. Prospective study of self-reported pain, radiographic osteoarthritis, sarcopenia progression, and falls risk in community-dwelling older adults. Arthritis Care Res. 2012;64(1):30-7.

14. Wright NC, Lisse JR, Walitt BT, Eaton CB, Chen Z, Nabel E, Rossouw J, Ludlam S, Pottern L, McGowan J, Ford L, Geller N, Prentice R, Anderson G, LaCroix A, Kooperberg CL, Patterson RE, McTiernan A, Shumaker S, Stein E. Arthritis increases the risk for fractures: results from the women's health initiative. J Rheumatol. 2011;38(8):1680-8.

15. World Health Organisation. International classification of functioning, disability and health. 1st ed. Geneva: WHO; 2001

16. Nevitt M, Felson D, Lester G. The Osteoarthritis Initiative. Protocol for the cohort study. National Institute of Arthritis, Musculoskeletal and Skin Disease.

17. Deandrea S, Lucenteforte E, Bravi F, Foschi R, La Vecchia C, Negri E. Risk factors for falls in community-dwelling older people: a systematic review and meta-analysis. Epidemiology. 2010;21(5):658.

18. Katz NJ, Chang CL, Sangha HO, Fossel WA, Bates WD. Can comorbidity be measured by questionnaire rather than medical record review? Med Care. 1996;34(1):73-84.

19. Radloff LS. The CES-D scale: a self-report depression scale for research in the general population. Appl Psychol Meas. 1977;1(3):385-401.

20. Roos EM, Roos HP, Lohmander LS, Ekdahl C, Beynnon BD. Knee injury and osteoarthritis outcome score (KOOS)--development of a self-administered outcome measure. J Orthop Sports Phys Ther. 1998;28(2):88.

21. McConnell S, Kolopack P, Davis AM. The Western Ontario and McMaster universities osteoarthritis index (WOMAC): a review of its utility and measurement properties. Arthritis Rheum. 2001;45(5):453-61.

22. Culvenor A, Wirth W, Roth M, Hunter D, Eckstein F. Predictive capacity of thigh muscle strength in symptomatic and/or radiographic knee osteoarthritis progression-data from the FNIH OA biomarkers consortium. Am J Phys Med Rehabil. 2016;95(12):931-8.

23. Osteoarthritis Initiative. Isometric Strength (Isometric Chair) Operations Manual version 1.2p 2008 [Available from: http://oai.epi-ucsf.org/ datarelease/operationsManuals/isometric_strengthv1_2p.pdf.

24. Goldberg A, Chavis M, Watkins J, Wilson T. The five-times-sit-to-stand test: validity, reliability and detectable change in older females. Aging Clin Exp Res. 2012;24(4):339-44.

25. Motyl JM, Driban JB, McAdams E, Price LL, McAlindon TE. Test-retest reliability and sensitivity of the 20-meter walk test among patients with knee osteoarthritis. BMC Musculoskel Disord. 2013;14:166.

26. Simonsick EM, Montgomery PS, Newman AB, Bauer DC, Harris T. Measuring fitness in healthy older adults: the health $A B C$ long distance corridor walk. J Am Geriatr Soc. 2001;49(11):1544-8.

27. Washburn RA, Montoye HJ. The assessment of physical activity by questionnaire. Am J Epidemiol. 1986;123(4):563.

28. Hosmer DW, Lemeshow S. Applied logistic regression. New York: Wiley; 2013.

29. Daoust R, Paquet J, Moore L, Emond M, Gosselin S, Lavigne G, Choiniere M, Boulanger A, Mac-Thiong JM, Chauny JM. Recent opioid use and fall-related injury among older patients with trauma. CMAJ. 2018;190(16):E500-E6.

30. Vestergaard P, Rejnmark L, Mosekilde L. Osteoarthritis and risk of fractures. Calcif Tissue Int. 2009;84(4):249-56.

31. Barker AL, Nitz JC, Low Choy NL, Haines TP. Mobility has a non-linear association with falls risk among people in residential aged care: an observational study. J Physiother. 2012;58(2):117-25.

32. Skou ST, Pedersen BK, Abbott JH, Patterson B, Barton C. Physical activity and exercise therapy benefit more than just symptoms and impairments in people with hip and knee osteoarthritis. J Orthop Sports Phys Ther. 2018; 48(6):439-47.

33. Sherrington C, Fairhall NJ, Wallbank GK, Tiedemann A, Michaleff ZA, Howard K, Clemson L, Hopewell S, Lamb SE. Exercise for preventing falls in older people living in the community. Cochrane Database Syst Rev. 2019;1(1): CD012424.

34. Hoffman GJ, Ha J, Alexander NB, Langa KM, Tinetti M, Min LC. Underreporting of fall injuries of older adults: implications for wellness visit fall risk screening. J Am Geriatr Soc. 2018:66(6):1195-200.

\section{Publisher's Note}

Springer Nature remains neutral with regard to jurisdictional claims in published maps and institutional affiliations. 